\title{
Optimization of a Draft Tube using Statistical Techniques- DOE and 2D Computational Fluid Dynamic Analysis
}

\author{
A. C. Barkett Botan ${ }^{\dagger}$, R. G. Ramirez Camacho, G. L. Tiago Filho and E. R. da Silva \\ Federal University of Itajuba, Itajuba-MG, 37500-903, Brazil \\ †Corresponding Author Email: acbotan@yahoo.com.br
}

(Received October 23, 2020; accepted May 3, 2021)

\begin{abstract}
The draft tube is one of the main components that integrate a turbine, since it has the function of recovering the residual kinetic energy after the runner by the pressure energy. The search for a draft tube design that increases the efficiency of the turbine is always an engineering challenge. The hydromechanics components geometry optimization can be accomplished through the integration of optimization methods and CFD tools. In this work, the geometric optimization of a double diffuser draft tube of a Bulb turbine applied to ultra-low heads is presented, with the objectives of maximizing the pressure recovery coefficient, $C_{p}$, and increasing the hydraulic efficiency of the turbine, $\eta_{h}$. These improvements would make it possible to reduce the longitudinal length of the draft tube, thereby, making an easier insertion of this kind of turbines in water transport systems, with pressures around $3\left[\mathrm{mH}_{2} \mathrm{O}\right]$. The optimization methodology was performed in the meridional plane, using twelve geometric variables in the draft tube through the integration of optimization methods and computational fluid dynamics. The optimized geometry obtained showed an increase in the $\mathrm{Cp}$ value of 0.71516 , from the original geometry, to 0.83080 . The results were extended to the $3 \mathrm{D}$ flow analysis, where the optimized turbine showed efficiency gains of $82 \%$ to $84 \%$, when compared to the original turbine considering that its total length was reduced and its geometry simplified, resulting in a more compact and versatile equipment. The study also concluded that the applied methodology can be extended to other similar optimization problems in the design of hydraulic machines.
\end{abstract}

Keywords: CFD analysis; Design of experiments; Draft tube; Bulb turbine; MOSA; Optimization.

\section{NOMENCLATURE}

$\mathrm{C}_{\mathrm{p}} \quad$ pressure recovery coefficient

d diameter

I turbulence intensity

K losses coefficient

$\mathrm{p} \quad$ static pressure

$p_{\text {in }} \quad$ in averaged static pressure at the inlet

$\begin{array}{ll}\text { Pout } & \text { averaged static pressure at the outlet } \\ \mathrm{v} & \text { velocity of the flow } \\ \eta_{\mathrm{h}} & \text { hydraulic efficiency } \\ \theta & \text { internal diffuser position angle } \\ \rho & \text { specific mass }\end{array}$

Subsequently, the models are tested on testing rigs, to evaluate their performance and, at the same time, validate the numerical models, so that the turbines can finally be manufactured within the quality standards required in the conceptual design.

Draft tube is a component of hydraulic turbines that plays an essential role for hydraulic efficiency gain. Conceptually, the draft tube recovers part of the kinetic energy dissipated after the fluid passes through the runner which would be wasted, by 
passing the flow through the expansion region of the draft tube, decreasing the flow speed, while increasing the pressure before discharge into the tailrace.

Nowadays, there are consolidated draft tube models according to the type of turbine and the type of installation. Nevertheless, optimization studies to increase performance of the draft tubes are still common. These optimization studies are carried out almost entirely using numerical simulations. The work by Straatman et al. (2017) presents the comparison of two different draft pipe tube geometries for Kaplan type "S" turbines. The optimization of these geometries aims the reduction of both costs and manufacturing time, by the reduction of the number of sections in the draft tube. As a result, the optimization conducted has increased hydraulic efficiency of the turbine by approximately $5 \%$, however, in a smaller flow field.

Rudolf (2006) and Moravec et al. (2016) present the optimization of the diffuser geometry of a draft tube of a Bulb turbine. Two optimization approaches were used, the first approach using the direct search method developed by Nelder-Mead (1965) applied to the first, second and third order Bezier curves, and the second approach using the Adjoint Solver optimization tool (Ansys Fluent $($ ). The use of different approaches aimed to compare the methods in order to obtain the best result. The objective of maximizing the pressure recovery coefficient, $C_{p}$, was used. As a result, the method that Nelder-Mead applied to the third-order Bezier curve achieved the best $C_{p}$ result with 0.813706 , compared with 0.812354 obtained by Adjoint Solver.

Mun et al. (2017), presents a multi-objective optimization method to improve the performance of draft tubes in hydraulic turbines where the design of the experiment (DOE), radial base functions (RBF) and genetic algorithm of non-dominated ordering (NSGA-II) are combined with CFD modelling. The objective-function used in the process corresponds to the maximization of the $C_{p}$, based on a problem governed by 9 design variables. As a result of the optimization process, the $C_{p}$ increased from 0.75 to 0.81 and the energy loss coefficient $(\zeta)$ decreased drastically from 0.21 to 0.12 .

Arispe et al. (2018) optimized the draft tube of the Francis GAMM turbine through hyperbolic and logarithmic arc curves in the elbow section. For the local and global analyses of the flow field, the CFX ${ }^{\circledR}$ software was used, with a $k-\omega$ SST turbulence model, verifying that the profile generated with the logarithmic curve presented lower losses coefficients, resulting in an increase of the hydraulic efficiency in the turbine.

Wilhelm et al. (2016) presents the flow field, in transient regime, for determining the losses of a draft tube of a Bulb turbine. In that work, the authors determined the behavior of the velocity profiles in several transversal planes in the length of the draft tube using LES (Large Eddy Simulation) and URANS (Unsteady Reynolds Averaged NavierStokes Equations) turbulence models. The solutions in LES and URANS were also compared with experimental data, verifying higher values of losses in the region of the wall and after the exit of the runner in the region downstream of the hub.

Other works have made great contributions to the optimization methods coupled with CFD tools. The work by Yang et al. (2010), in which he applies DOE and response surfaces (RSM) based optimization, in the parameterization of the geometry of the blades of a Bulb turbine, by changing the position of the points to generate the spline curve. Therefore, the variation of the Bezier spline curve is adopted to maintain the blade surface without irregularities. The $k-\omega$ SST turbulence model was used. The numerical scheme for the convective term was second-order upwind, and for the diffusive term, it was the second-order center. The coupling method for pressure and velocity was SIMPLE. The total pressure was defined as the boundary condition at the inlet, whereas the static pressure was the boundary condition at the outlet. The authors have found that blade optimization had improved the hydraulic efficiency, as well as it had reduced the losses in the draft tube

Silva et al. (2010) describes techniques for coupling optimization algorithms with the generation of response surfaces using radial base functions, applied to the representative grid case and to an axial turbomachine runner. For the optimization process, Controlled Random Search Algorithm (CRSA) algorithms were used. In the case of the grid (2D), lateral restrictions such as assembly angle position, arching of the NACA65 series profile and grid spacing were defined, in order to maximize the ratio of lift and drag coefficients. In the case of the axial turbine runner (3D), the same restrictions were considered, but the objective-function was to maximize hydraulic efficiency. This methodology allows to quickly and efficiently reach an optimal solution of the linear grid or runner design.

For the optimization of an axial turbine with very low heads, Muis et al. (2015) proposes two methodologies, the first being the study and modification of the blade profile, and the second, the study based on the grid of the turbine blade. In the first methodology, the optimization method was performed using the XFOIL ${ }^{\circledR}$ software, controlled via Matlab ${ }^{\circledR}$. The method aims to obtain the optimum ratio between the lift and drag forces over a range of angles of attack, $\alpha$. In the second methodology, it was aimed to obtain the optimal criteria of the grid. These criteria are: optimum inlet and outlet flow angles on the blades, shock-free conditions and minimum suction pressure criteria. To obtain these criteria, a Matlab ${ }^{\circledR}$ code is used. The turbines obtained using the applied methodologies were analyzed via CFD using the Ansys Fluent ${ }^{\circledR}$ software, with $k-\omega$ SST as the turbulence model. As a result, the turbine based on the first methodology achieved an efficiency of $91.36 \%$, whereas the turbine based on the second methodology obtained $91.27 \%$, both under the same contour and operation conditions. 


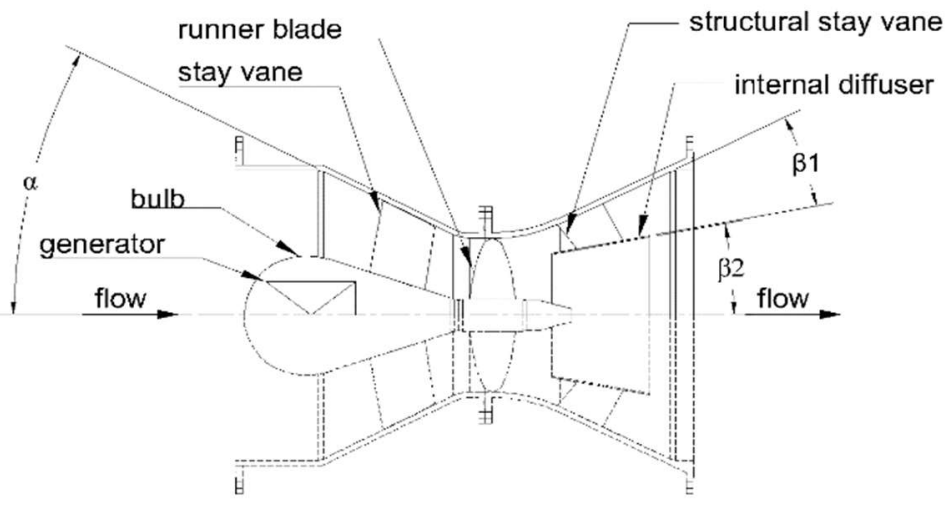

Fig. 1. UHL Turbine geometry (Martin et al. 2016).

Dehghami et al. (2016) uses of the two-dimensional approach in the optimization of the diffuser of an axial turbine. The optimization problem uses from three to nine variables, represented by construction points of the spline curve that forms the diffuser wall. The problem is solved by integrating CFD software and code developed by Matlab® ${ }^{\circledR}$.

Chirkov et al. (2018) describes the optimization of the blades of a Francis runner, taking into account hydraulic efficiency, mechanical strength and the weight of the rotor. To solve the optimization problem, a multi-objective genetic algorithm was used.

Other works that relate the integration of optimization methods with CFD can be cited, such as Vinagre et al. (2016), Amani et al. (2018), Bhattarai et al. (2018), Adanta et al. (2018), Iovanel et al. (2019.a,b), Santos et al. (2019), Daniels et al. (2020) and Khanjanpour and Javadi (2021).

Pinto et al. (2017) describes a complete revision and state of the art on the use of CFD tools in turbomachinery, and these turbines, compressors and centrifugal pumps. It is necessary to emphasize that this type of work is of great importance because it comes to assist the users of these tools in the solution of the numerical problems that they come to study. In the same way, this reflection can be extended to Kumar et al. (2020), where the authors discuss a specific case of structural analysis of a gas turbine using numerical tools. It is important to observe in the numerical solution of the Navier Stokes equation that not only the finite volume technique may be the most indicated considering the processing time when integrated with optimization algorithms. Thus, the boundary elements method, BEM, and the nonviscous interaction models are methodologies with low processing time, as shown by the works of Camacho and Barbosa (2005, 2008), Camacho and Manzanares Filho (2005) and Castilho et al. (2016).

\subsection{Research gap and motivation}

Turbomachinery projects require optimization studies to obtain a more efficient machine. Since the tests of these machines are based on the construction of physical models to be tested in very expensive testing rigs, the option of using computational fluid dynamics tools becomes the most economical option, until the definitive optimized model is obtained. However, the entire automated optimization process, using numerical codes based on the threedimensional approach (Zhou et al. 2019; Herrera et al. 2017; McNabb et al. 2014; Nam et al. 2018 and Orso et al. 2020) has a high computational cost. This work presents a proposal for a methodology to optimize a hydraulic ultra-low head turbine (ULH) with the modification of the draft tube geometry, aiming to increase the efficiency of the machine by obtaining a higher $C_{p}$ value, using a two-dimensional approach, which aims to decrease computational cost.

In the current optimization study, the methodology is applied to the special geometry draft tube of the ULH turbine. The draft tube is a very important component of the turbine, and many studies focus on optimizing the draft tube to obtain efficiency gains from the turbine (Daniels et al. 2020; Herrera et al. 2017; McNabb et al. 2014; Nam et al. 2018; Galván et al. 2013; Orso et al. 2020 and Dehghami et al. 2016). The references Muhirwa et al. (2020), Abbas and Kumar (2017) and Pal (2018) present a review of the use of the draft tube in their works, providing constructive and theoretical details, as well as comparative studies based on computational fluid dynamics.

The draft tube from the current paper has characteristics of reduced axial length, which requires an angle of conic expansion greater than 8 degrees (Fig. 1), generally adopted in smooth stretches, resulting in longer lengths. Therefore, it is possible to introduce a conical diffuser with a hydrodynamic profile inside the draft tube in order to control the separation of the boundary layers, reduce the levels of turbulence and the formation of secondary flows, resulting in a reduction of the loss coefficient in the tube and increased hydraulic efficiency of the turbine. For the optimization process of the draft tube, DOE and population algorithms were used, integrated to the CFD solutions.

\subsection{Contribution and paper organization}

The two-dimensional flow machine optimization approach proposed in this work is not so widespread, 
and three-dimensional models are often used, as results are closer to reality. However, it is possible to obtain qualitative results through two-dimensional models, especially considering the large number of problems that can be solved in less computational time. It is then possible to determine through the population of results the one that reaches the maximum value of the objective function, and then to verify the results and behavior through a single three-dimensional analysis. This process, as presented in this work, results in a process with lower computational cost and concludes in a turbine with greater efficiency compared to its original design. Similar proposals involving optimization with the integration of CFD, algorithms and metamodels are presented in Sarmiento et al. (2020, 2021), Rezek et al. 2021, Silva et al. (2012), and Dehghami et al. (2016).

This paper is structured as follows: in section 1, the literature review, the gap and the motivation of the study are presented and its contribution; in section 2 is presented the description of the ultra-low head turbine; in section 3 is descripted the optimization strategy; in section 4 are presented the 2D CFD analysis of the draft tube and its results; in section 5 the 3D CFD analysis of the draft tube and its results; in section 6 are presented the 3D CFD analysis of the optimized turbine and the comparison of results to the original turbine; and finally, in section 7 are presented all the conclusions of the study.

\section{ULTRA-LOW HEAd TURBINE GEOMETRY}

The development of technologies for small and micro generation contributes to the supply of decentralized electricity in remote communities, especially in developing countries. Furthermore, it also has a positive impact on the industry and the economy, due to the fact that it is relatively less harmful to the environment and due to the large-scale exploitation of resources that have already been exploited by large hydroelectric plants.

Thus, the hydro-energy utilization of ultra-low head turbines does not require the construction of large dams to control heads and flow, and can often take advantage of the natural slopes in river courses. Since there is no need to use dams, it is considered that the turbomachine operates under variable conditions, therefore, its rotation is not constant.

The references Zhou and Deng (2017) and Sritram and Suntivarakorn (2017) present detailed reviews and states of the art on ULH harnessing technologies. Zhou et al. (2019) introduces a study on the development of a Siphon type turbine based on CFD analysis. The turbine developed for the Gaoliangjian plant achieved a hydraulic efficiency of $87.9 \%$ when operated on ultra-low falls of 2.87 [m]

The initial configuration of the ultra-low head turbine is based on the work of Martin et al. (2016). The ULH Turbine (Ultra-Low Head Turbine), which prototype has a runner with diameter of $0.75[\mathrm{~m}]$, operates on heads that vary between 0.5 and 2.5 [m] and with variable rotation. In Fig. 1, the geometry of the turbine is presented, consisting of a guide-vane system with six fixed blades, a runner with three fixed blades and a draft tube with conical diffuser inside. The draft tube also has four fixed blades, to fix the internal diffuser and direct the flow in the region between walls.

Its configuration, as shown in Fig. 1, demonstrates the possibility of installing this turbine in different water conditions, from the aforementioned natural slopes in river courses, small dams, matrix installations in dams, irrigation channels, and water transport systems in pipelines, in the case of the model presented in this work, of around $3\left[\mathrm{mH}_{2} \mathrm{O}\right]$.

\section{OPTIMIZATION STRATEGY}

The optimization techniques are widely used in turbomachinery, however, a detailed description of all optimization algorithms would not be possible, so it is intended to present the general basis of the techniques that were applied in this work.

Optimization is defined as the search process to obtain the best result from a maximization or minimization problem, in a predetermined region of possible solutions. On the other hand, it is important to emphasize that the designer who works in the development of the preliminary project identifies, based on his own experience, the range of values of the design variables that can be optimized considering the stages of manufacture and final assembly. In this case, it is possible to consider all these uncertainties in the design of the machine, through robust optimization concepts.

Technically, an optimization problem is characterized by the maximization or minimization of one or multiple objective-functions, based on the design variables, which may or may not be limited by design restrictions (Montgomery 2005; Rao 2009).

In the present work, despite the use of only one objective function, the search method employed is multi-objective, like MOSA. Mathematical problems with multiple objectives have several solutions (Nam and Hoon Park, 2000). These problems consist of obtaining a set of variables that satisfy the imposed restrictions and optimize a function, made up of several terms or objective-functions.

\subsection{Multi-objective Simulated Annealing Method - MOSA}

Simulated Annealing (SA) is a stochastic local search algorithm, which uses the principles of statistical mechanics, which is based on an analogy with thermodynamic principles (Nam and Hoon Park 2000; Bandyopadhyay et al. 2008; Ulungu et al. 1999) presented for the first time by Kirkpatrick et al. (1983). In Gosavi (2003), the author describes in five steps the solution of a Simulated Annealing algorithm, as reproduced and described below:

(a) Choose an initial solution $\vec{x}_{\text {current }} \vec{x}_{\text {current }}$ Be $f(\vec{x})$ the value of the objective-function in $\overrightarrow{\mathrm{x}}$ 
(obtained by simulation). Be $\overrightarrow{\mathrm{x}}_{\text {best }}$ the best solution. $\overrightarrow{\mathrm{x}}_{\text {best }} \leftarrow \overrightarrow{\mathrm{x}}_{\text {current }}$

(b) Determine a pre-specified value for $\mathrm{T}$ (temperature). The temperature will be gradually reduced in discrete steps. But for each temperature, Steps 2 and 3 will be performed for a number of iterations. This is called a phase. For each phase it will consist of several iterations. The number of iterations for each phase is expected to increase with the number of phases. The algorithm is written to minimize the objective-function.

Step 1. Determine the phase number, $\mathrm{P}$, in 0 .

Step 2. Randomly select a neighbor from the current solution. Indicate the neighbor by $\vec{x}_{\text {new }}$.

Step 3. If $f\left(\vec{x}_{\text {new }}\right)<f\left(\vec{x}_{\text {best }}\right)$,, establish: $\overrightarrow{\mathrm{x}}_{\text {best }} \leftarrow \overrightarrow{\mathrm{x}}_{\text {new }}$.

Be: $\Delta=\mathrm{f}\left(\overrightarrow{\mathrm{x}}_{\text {new }}\right)-\mathrm{f}\left(\overrightarrow{\mathrm{x}}_{\text {current }}\right)$, otherwise, that is, if $\Delta>0$, generates a random number uniformly distributed between 0 and 1 and calls it $U$

If: $U \leq \exp \left(-\frac{\Delta}{\mathrm{T}}\right)$, then, establish $\overrightarrow{\mathrm{x}}_{\text {current }} \leftarrow \overrightarrow{\mathrm{x}}_{\text {new }}$ otherwise, do not change the $\vec{x}_{\text {current }}$.

Step 4. An execution of Steps 2 and 3 constitutes an iteration of a phase. Repeat Steps 2 and 3 until the number of iterations associated with the current phase is performed. When these iterations are performed, proceed to Step 5 .

Step 5. Increase the number of the $P$ phase by 1 . If $\mathrm{P}<\mathrm{P}_{\max }$, reduce $\mathrm{T}$ and go back to Step 2 for another phase. Otherwise, close the algorithm and declare $\overrightarrow{\mathrm{x}}_{\text {best }}$ for the best solution obtained.

MOSA is a method adapted from SA where the global search extends to more than one objective function. According to Nam and Hoon Park (2000), MOSA uses the concept of domination and the annealing scheme for an efficient search. The main obstacle for SA in multi-objective optimization is its inability to find several solutions. However, SA can do the same job by repeating the attempts, as it converges to the global optimum with a uniform probability distribution in the optimization of a single objective. When there are two global optimums, it is proven that the SA can find each with a $50 \%$ probability. In addition, MOSA can find a small group of Pareto front solutions in a short time considering the urgent simulation demand and then find other solutions by repeating the tests in order to obtain detailed information on the Pareto frontier.

\subsection{Design of Experiments - DOE}

To start an optimization procedure considering, for example, a flow machine, the design variables to be optimized must be defined. The design of experiments (DOE) consists of a statistical technique that allows different ways to combine the design variables within the minimum and maximum lateral limits defined by the designer. The strategy is commonly used for optimization problems, which consists of maximizing or minimizing performance in mono-objective situations, or in multi-objective situations, such as increasing efficiency and reducing losses in flow, or even in multidisciplinary problems, which in addition to involving more than one objective function, involves functions from other areas of study, such as including in the mentioned multi-objective situation, noise reduction, material cost, or manufacture of the turbomachinery. DOE can be generated in different ways, the most common of them are: Random, Full-Factorial, Latin Hypercube, among others. In this work, it was decided to use the DOE Random, because the problem studied in this work has a very large number of variables, thus, the use of other methods, such as Full-Factorial, for example, would be impracticable, due to the large number of combinations that would be generated.

According to Montgomery (2005), statistical methods require combinations to be randomly distributed, independently. Thus, randomization generally makes this assumption valid.

\subsection{Optimization problem}

The proposed optimization problem seeks to modify the geometric shapes of the external expansion tube and the hydrodynamic profile of the internal suction tube diffuser. In order to analyze the results, geometric variations were proposed, as described in Table 1 (the differences on the geometries can be seen in Fig. 4). In a first approach, the optimization technique was applied in a two-dimensional model in the meridional plane, where control variables of the draft tube and internal diffuser geometry were adopted, as shown in Fig. 2. As a mono-objective function, the pressure recovery coefficient $(C p)$ was chosen, as it is a variable associated with the performance defined by Eq. (1). Besides MOSA is considered as optimization algorithm, it can be applied to mono-objective problems as well. In this sense, the chosen objective function was chosen to maximize $C_{p}$.

Table 1 Draft tube geometries.

\begin{tabular}{|l|l|}
\hline Geometry & Description* \\
\hline $\mathrm{GEO}_{01}$ & Straight wall draft tube, with internal diffuser cone with flat profile $(\mathrm{L}=671 \mathrm{~mm})$ \\
\hline $\mathrm{GEO}_{02}$ & Straight wall draft tube, without internal diffuser $(\mathrm{L}=671 \mathrm{~mm})$ \\
\hline $\mathrm{GEO}_{03}$ & Straight wall draft tube straight, without internal diffuser and extended length $(\mathrm{L}=800 \mathrm{~mm})$ \\
\hline $\mathrm{GEO}_{04}$ & Curved wall draft tube, with hydrodynamic profile diffuser $(\mathrm{L}=500 \mathrm{~mm})$ \\
\hline $\mathrm{GEO}_{05}$ & Curved wall draft tube, with hydrodynamic profile diffuser - optimized $(\mathrm{L}=500 \mathrm{~mm})$ \\
\hline
\end{tabular}




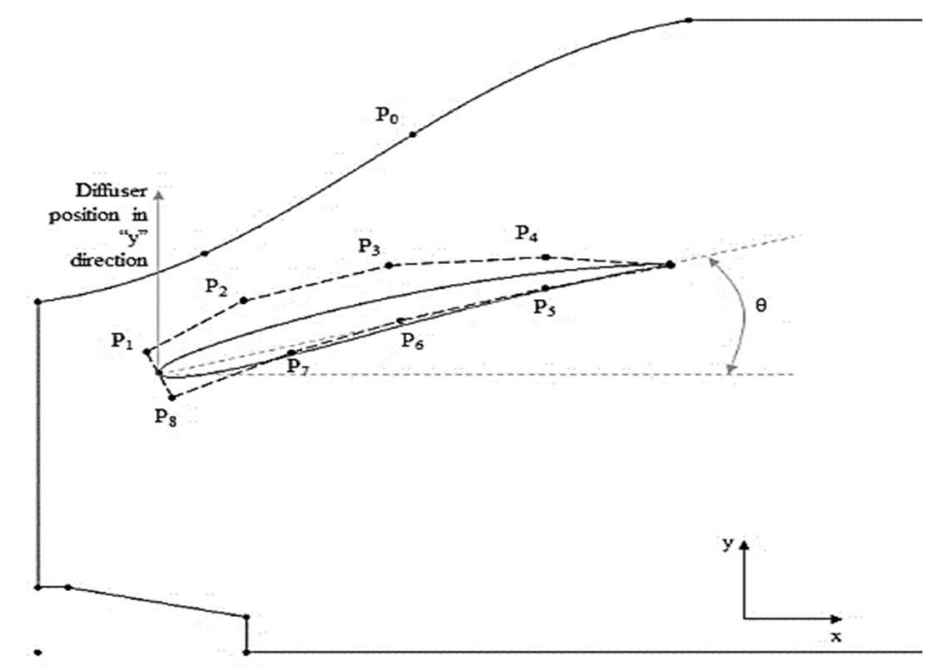

Fig. 2. Optimization control variables for the draft tube and internal diffuser.

The $C_{p}$ indicates the amount of conversion of kinetic energy into static pressure, therefore, a higher value indicates a greater efficiency of the turbine, due to the performance of the draft tube (Mun et al. 2017).

For a given diffuser area ratio, the greater the pressure recovery, the lesser are the losses. Therefore, it is desired that the $C_{p}$ value be as high as possible, where pin is the average static pressure at the inlet of the suction tube, pout is the average static pressure at the outlet to the tailrace, $\rho$ is the density of water and $v$ is the average velocity at the inlet of the suction tube. The losses coefficient $K(<1.0)$ is obtained as a function of the ratio of diffuser diameters $(<1.0)$ and $C_{p}$, according to Eq. (2).

$$
\begin{aligned}
& C_{p}=\frac{p_{\text {in }}-p_{\text {out }}}{\frac{1}{2} \rho v^{2}} \\
& K=1-\frac{d_{1}^{4}}{d_{2}^{4}}-C_{p}
\end{aligned}
$$

The optimization methodology is applied on the $\mathrm{GEO}_{04}$ geometry to obtain the optimized $\mathrm{GEO}_{05}$ geometry. DOE Random was first constructed, considering 12 geometric variables, being: 8 Bezier polynomial control points that define the hydrodynamic profile of the diffuser; 1 variable for the position of the diffuser in the $y$ direction, 1 variable for the diffuser position angle $(\theta)$ and 2 variables for the positions in the $x$ and $y$ directions of the intermediate point $P_{0}$, where the two cubicles are located, as shown in Fig. 2, resulting in a DOE with 36 combinations.

To integrate the optimization processes and the numerical solution in CFD, a Fortran ${ }^{\circledR}$ program was developed in order to apply the optimization methodology through the integration of the DOE and the MOSA optimization algorithm. To automate the optimization process with the computational fluid dynamics tools, the automatic generation of the geometry and meshes was performed by editing commands in $\mathrm{Tcl} / \mathrm{Tk}$ language for interpretation by the Icem CFD ${ }^{\circledR}$ software. To define the boundary conditions and numerical solution schemes, an auxiliary file (journal.jou) was introduced for automatic interpretation by Fluent ${ }^{\circledR}$, as shown in the flowchart in Fig. 3.

The cubic interpolation curve that controls the geometry of the tube expansion wall is defined by the extreme points between the inlet and outlet of the tube and the intermediate point $P_{0}$ (Fig. 2). The longitudinal length of the draft tube of the $\mathrm{GEO}_{04}$ and GEO $_{05}$ geometries is $500[\mathrm{~mm}]$, that is, its length is less than $671.32[\mathrm{~mm}]$ of the original geometry, forcing the reduction of the longitudinal size of the suction tube by a considerable amount.

The internal diffuser has a hydrodynamic section generated by 5 control points, that are defined by Bezier polynomials on the suction side, and 5 points on the pressure side, initially defined based on the NACA 6409 profile, and positioned at $\theta=10.6$ degrees with respect to the line horizontal axis. The Bezier polynomial of degree $n$ is defined by Eq.'s (3) and (4).

$$
\begin{aligned}
& x(t)=\sum_{t=0}^{n} \frac{n !}{i !(n-i) !} t^{i}(1-t)^{n-i} X_{i} \\
& y(t)=\sum_{t=0}^{n} \frac{n !}{i !(n-i) !} t^{i}(1-t)^{n-i} Y_{i}
\end{aligned}
$$

Figure 2 shows the control points and the geometry generated for a hydrodynamic profile for the case of $\mathrm{GEO}_{04}$ geometry. The initial values and the lateral limits established for the optimization of the design variables are shown in Table 2.

The flowchart in Fig. 3 shows the optimization process managed by Fortran ${ }^{\circledR}$ software that allows automatic integration between CFD solutions and the optimization algorithm MOSA. 


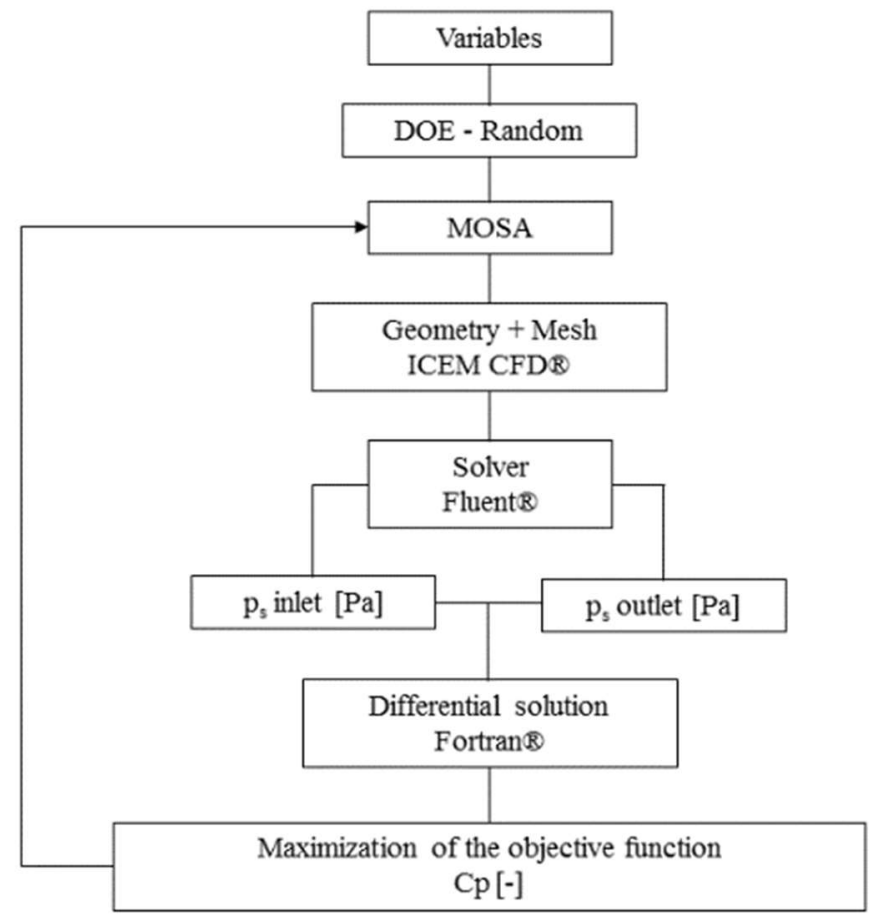

Fig. 3. Flowchart of the optimization process.

Table 2 Project variables.

\begin{tabular}{|c|c|c|c|c|}
\hline \multirow[b]{2}{*}{. } & & & \multicolumn{2}{|c|}{ Lateral limits } \\
\hline & Variable & Initial value & Min value & Max value \\
\hline \multirow{5}{*}{ 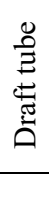 } & Diffuser position angle $-\theta$ [degrees] & 10.6 & 8 & 15 \\
\hline & Diffuser position y [mm] & 300 & 300 & 365 \\
\hline & $\mathrm{P}_{0}(\mathrm{x})[\mathrm{mm}]$ & 325 & 315 & 335 \\
\hline & $\mathrm{P}_{0}(\mathrm{y})[\mathrm{mm}]$ & 577.2 & 565 & 585 \\
\hline & \multicolumn{4}{|c|}{ Control points of the Bezier curve, variations in the y direction [mm] } \\
\hline \multirow{10}{*}{ 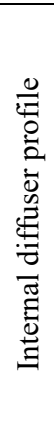 } & \multicolumn{4}{|c|}{ Suction side } \\
\hline & $\mathrm{P}_{1}(\mathrm{y})$ & 305 & 305 & 325 \\
\hline & $\mathrm{P}_{2}(\mathrm{y})$ & 321.6 & 321.6 & 340 \\
\hline & $\mathrm{P}_{3}(\mathrm{y})$ & 322.2 & 322.2 & 345 \\
\hline & $\mathrm{P}_{4}(\mathrm{y})$ & 314.4 & 314.4 & 335 \\
\hline & \multicolumn{4}{|c|}{ Pressure side } \\
\hline & $\mathrm{P}_{5}(\mathrm{y})$ & 303.7 & 285 & 303.7 \\
\hline & $\mathrm{P}_{6}(\mathrm{y})$ & 304.2 & 285 & 304.2 \\
\hline & $\mathrm{P}_{7}(\mathrm{y})$ & 301.5 & 280 & 301.5 \\
\hline & $\mathrm{P}_{8}(\mathrm{y})$ & 295 & 275 & 295 \\
\hline
\end{tabular}

\section{TWO-DIMENSIONAL CFD ANALYSIS OF THE DRAFT TUBE}

\subsection{D model mesh}

In all developed geometries (2D), structured meshes were built, based on the blocking technique. With this, it is possible to have greater control over the elements created, ensuring greater quality to the mesh. The size of the elements close to the wall was determined for $y^{+}$around 10 , with a growth rate of 1.2 , resulting in elements with a height of $0.01 \mathrm{~mm}$ in these regions.

\subsection{Numeric solution}

\subsubsection{Equations of motion and turbulence models}

Before starting simulation, physical principles of the problem must be known, considering the flow as incompressible, with two conservation equations in steady regime, representing the flow in a hydraulic turbine, being: the equation of mass conservation and quantity of motion in non-inertial system (relative velocity). For the inertial system, the equations are based on absolute velocity without the effects of apparent accelerations. All the equation are 
presented in Einstein's notation in cartesian coordinates.

$$
\begin{aligned}
& \frac{\partial w_{i}}{\partial x_{i}}=0 \\
& \rho w_{k} \frac{\partial w_{j}}{\partial x_{k}}+\rho\left(\vec{a}_{c}+\vec{a}_{n}\right)= \\
& -\frac{\partial}{\partial x_{j}}\left(\rho^{*} \delta_{i j}\right)+\mu \frac{\partial}{\partial x_{i}}\left(\frac{\partial w_{j}}{\partial x_{i}}+\frac{\partial w_{i}}{\partial x_{j}}\right)
\end{aligned}
$$

where:

$\rho$ is the specific fluid mass $\left[\mathrm{kg} / \mathrm{m}^{3}\right], w_{i}$ is the relative velocity $[\mathrm{m} / \mathrm{s}], p^{*}$ is the moving static pressure $[\mathrm{Pa}]$, $\mu$ is the dynamic viscosity $[\mathrm{kg} / \mathrm{m} . \mathrm{s}], \vec{a}_{c}=2 \vec{\Omega} \times \vec{w}$ is the Coriolis acceleration $\left[\mathrm{m} / \mathrm{s}^{2}\right]$ and $\vec{a}_{n}=\vec{\Omega} \times(\vec{\Omega} \times \vec{r})$ is the normal acceleration $\left[\mathrm{m} / \mathrm{s}^{2}\right]$.

For the determination of the Reynolds-averaged Navier Stokes equations for incompressible flow, the system of equations Eq. 5 and 6 are decomposed in an average value plus a component of temporal fluctuation $w(t)=W+w(t)$, (in the relative flow,

for example). Thus, for a stationary, incompressible and Newtonian fluid, one can obtain the Reynolds equation in Einstein's notation in Cartesian coordinates, such as:

$$
\begin{aligned}
& \rho \bar{w}_{k} \frac{\partial \bar{w}_{j}}{\partial x_{i}}+\rho\left(\vec{a}_{c}+\vec{a}_{n}\right)= \\
& \frac{\partial}{\partial x_{j}}\left[-\rho^{*} \delta_{i j}+\mu\left(\frac{\partial \bar{w}_{j}}{\partial x_{i}}+\frac{\partial \bar{w}_{i}}{x_{j}}\right)-\rho \bar{w}_{i}^{\prime} \bar{w}_{j}^{\prime}\right]
\end{aligned}
$$

On the other hand, according to Boussinesq's hypotheses, it is possible to relate the Reynolds stresses (Eq. 7) through the turbulent viscosity and the mean rates of deformation, given by:

$$
-\rho \bar{w}_{i}^{\prime} \bar{w}_{j}^{\prime}=-\mu_{t}\left(\frac{\partial \bar{w}_{i}}{\partial x_{j}}+\frac{\partial \bar{w}_{j}}{\partial x_{i}}\right)-\frac{2}{3} \rho k \delta_{i j}
$$

where $k=1 / 2\left(\bar{w}_{1}^{2}+\bar{w}_{2}^{\prime 2}+\bar{w}_{3}^{\prime 2}\right)$ is the turbulent kinetic energy per mass unit and $\mu_{t}$ is the eddy viscosity. There is also the kinematic turbulent viscosity denoted by $v_{t}=\mu_{t} / \rho\left[\mathrm{m}^{2} / \mathrm{s}\right]$.

To close the system of equations, it is necessary to determine the turbulent viscosity, being this modeled using other scalar transport equations such as, for example, $k-\varepsilon$ and $k-\omega$.

Wilcox k- $\omega$ model

The turbulence models will be presented for the inertial or absolute system, however, considering the relative field the variable $U_{i}$ can be replaced by the relative speed $W_{i}$, without losing the generality of the analysis.

The $k-\omega$ turbulence model is also based on two scalar transport equations, in which dissipation term is calculated based on vorticity. The model proposed by Wilcox $(1988,1993,1994)$, uses the turbulence frequency $\omega=\varepsilon / k(\mathrm{~s}-1)\left[\mathrm{s}^{-1}\right]$ and the length scale is $l=\sqrt{k} / \omega$ defined as $l=k^{3 / 2} / \varepsilon$.

The eddy viscosity is given by turbulent viscosity, defined as: $\mu_{t}=\rho k / \omega$, thus, the new equations for $k$ and $\omega$ are:

$$
\begin{aligned}
& \frac{\partial(\rho k)}{\partial t}+U_{j} \frac{\partial(\rho k)}{\partial x_{j}}=\frac{\partial}{\partial x_{j}}\left[\left(\mu+\frac{\mu_{t}}{\sigma_{k}}\right) \frac{\partial k}{\partial x_{j}}\right]+ \\
& \left(2 \mu_{t} S_{i j} S_{i j}-\frac{2}{3} \rho \omega \frac{\partial U_{i}}{\partial x_{j}} \delta_{i j}\right)-\beta^{*} \rho k \omega
\end{aligned}
$$

$$
P_{k}
$$

$\frac{\partial(\rho \omega)}{\partial t}+U_{j} \frac{\partial(\rho \omega)}{\partial x_{j}}=\frac{\partial}{\partial x_{j}}\left[\left(\mu+\frac{\mu_{t}}{\sigma_{\omega}}\right) \frac{\partial \omega}{\partial x_{j}}\right]+$

$\gamma_{1}\left(2 \rho S_{i j} \cdot S_{i j}-\frac{2}{3} \rho \omega \frac{\partial U_{i}}{\partial x_{j}} \delta_{i j}\right)-\beta_{1} \rho \omega^{2}$

$S_{i j}=\left(\frac{\partial U_{i}}{\partial x_{j}}+\frac{\partial U_{j}}{\partial x_{i}}\right)$

$\sigma_{k}=2.0, \sigma_{\omega}=2.0, \gamma_{1}=0.553, \beta_{1}=0.075, \beta^{*}=0.09$

Menter SST k- $\omega$ model

There is a combination of $k-\varepsilon$ and $k-\omega$ models resulting in $k-\omega$ SST model, with the advent of Shear Stress Transport (SST) methodology. This model was initially proposed by Menter (1994) with the purpose of modeling turbulence with variation of pressure gradient and separation of boundary layer in flow (Launder and Spalding 1974; Yakhot et al. 1992).

Thus, fundamental equations of this model are presented, turbulence kinetic energy is represented by $\mathrm{Eq}(9)$ and new equation for specific dissipation rate:

$\frac{\partial(\rho \omega)}{\partial t}+U_{j} \frac{\partial(\rho \omega)}{\partial x_{j}}=\frac{\partial}{\partial x_{j}}\left[\left(\mu+\frac{\mu_{t}}{\sigma_{\omega 1}}\right) \frac{\partial \omega}{\partial x_{j}}\right]+$

$\gamma_{2}\left(2 \rho S_{i j} S_{i j}-\frac{2}{3} \rho \omega \frac{\partial U_{i}}{\partial x_{j}} \delta_{i j}\right)-\beta_{2} \rho \omega^{2}+$

$2\left(1-F_{1}\right) \frac{\rho}{\sigma_{\omega 2} \omega} \frac{\partial k}{\partial x_{k}} \frac{\partial \omega}{\partial x_{k}}$

$\sigma_{k}=1.0, \sigma_{\omega 1}=2.0, \sigma_{\omega 2}=1.17, \gamma_{2}=0.44, \beta_{2}=$

$0.083, \beta^{*}=0.09$.

In the last term of Eq. (12), the term $\mathrm{F}_{1}$ is introduced for turbulence model $k$ - $\omega$ SST. Menter (1994) defines regions close to wall as $F_{1}=1$ and, for regions away from the wall, as $F_{1}=0$. If $F_{1}=0$ the Eq. (12) is transformed in the equation for turbulence dissipation $\varepsilon$ using the relation $\omega=\varepsilon / k$. However, when there is a mesh, which it has three regions (close to the wall, away from the wall and the central region), it is possible to obtain a weight function to 
define central region through the argument of the hyperbolic tangent function ( $\tanh$ ), with a slight variation between limits of 0 and 1 , as shown in Fig. 4.

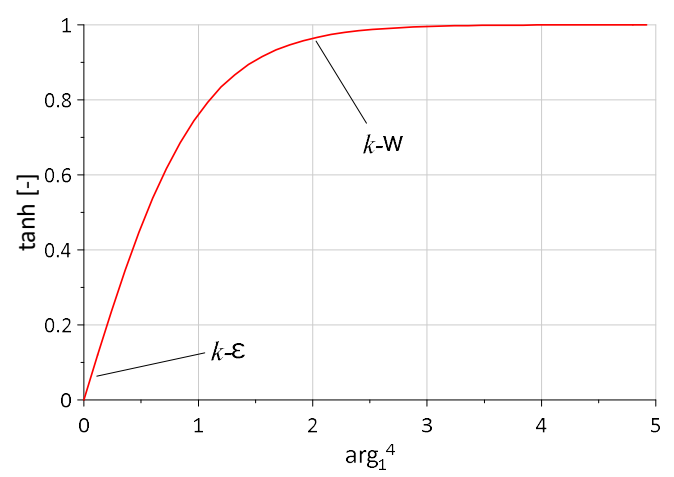

Fig. 4. Function $F_{1}=\tanh \left(\arg _{1}^{4}\right)$.

$\arg _{1}=\min \left[\max \left(\frac{\sqrt{k}}{\beta^{*} \omega d}, \frac{500 v}{d^{2} \omega}\right), \frac{4 \rho \sigma_{\omega 2} k}{C D_{k \omega} d^{2}}\right]$

$C D_{k \omega}=\max \left(2 \rho \frac{1}{\sigma_{\omega 2} \omega} \frac{\partial k}{\partial x_{i}} \frac{\partial \omega}{\partial x_{i}}, 1.0 E^{-10}\right)$

Variable 'd' in Eq. (15) represents the perpendicular distance between wall and nodal point of element or control volume, so that in each nodal point functions of argument are calculated and evaluated according to maximum and minimum functions. On the other hand, the constants of $k-\varepsilon$ and $k-\omega$ models, are calibrated through the mixing functions, $\phi=F_{1} \phi_{\omega}+\left(1-F_{1}\right) \phi_{\varepsilon}$. If $F_{1}=1$, so $\phi=\phi_{\omega}$ that implies the use of the $k$ - $\omega$ model by introducing the constant $\beta^{*}$. If $F_{1}=0$, so $\phi=\phi_{\varepsilon}$ that implies the use of the $k$ - $\varepsilon$ model with the constant $C_{\mu}$, defined as $\varepsilon=C_{\mu} k \omega$.

Eddy viscosity is limited to give improved performance in flows for adverse pressure gradients and wake regions. In this sense, the turbulent kinetic energy production is limited to prevent the build-up of turbulence in stagnation regions. Limiters are as follows.

$\mu_{T}=\frac{5 / 9 \rho k}{\max \left(5 / 9 \omega, \sqrt{2 S_{i j} S_{i j}} F_{2}\right)}$

$F_{2}=\tanh \left\{\left[\max \left(\frac{2 \sqrt{k}}{\beta^{*} \omega y}, \frac{500 v}{d^{2} \omega}\right)\right]^{2}\right\}$

Turbulent kinetic energy production term now is evaluated by minimization function as:

$$
P_{k}=\min \left(10 \beta^{*} \rho k \omega, 2 \mu_{t} S_{i j} S_{i j}-\frac{2}{3} \rho k \frac{\partial U_{i}}{\partial x_{j}} \delta_{i j}\right)
$$

The $k-\omega$ SST model gives better agreement with experiments of mildly separated flow. This is primarily due the viscosity limiter. Hence, this model is appropriate for external and internal flows, as example the flow in the periodic hydraulic channel.

\subsubsection{Numerical model}

2D computational numerical analysis was performed on the Fluent ${ }^{\circledR}$ software, in permanent regime. The turbulence model adopted was the $k$ - $\omega$ SST, with wall functions to quantify the turbulent viscosity (Menter 1994). For the boundary conditions, it used the velocity components in $x$ and $y$ directions and also the static pressure in the inlet region of the draft tube. These data were obtained by a previous $3 \mathrm{D}$ simulation of the turbine, with the resulting components of velocity and pressure after the runner exported, processed, and used as external data. In the outlet region of the draft tube, a static pressure value equal to zero [Pa] was applied. The SIMPLE method was used as a coupling technique between pressure and velocity. For the numerical schemes for the pressure, the Standard and First-Order Upwind methods were used for the convection term. Relaxation factors were adopted for the momentum and for turbulent kinetic energy of 0.4 and 0.5 respectively. Residuals were monitored at $10^{-4}$ for the momentum components and $10^{-3}$ for $\mathrm{k}$ and omega. Global variations in static pressures at the inlet and outlet regions of the domain and mass flow were also monitored.

\subsection{Two-dimensional analysis results of the flow in the draft tube}

As shown in Table $3, \mathrm{GEO}_{01}$ geometry showed the lowest value of $C_{p}=0.7151$. The $\mathrm{GEO}_{02}$ geometry showed a considerable increase in the $C_{p}$ value in 0.7354 , being improved to 0.7408 with the increase in length in $\mathrm{GEO}_{03}$.

Table 3 Pressure recovery coefficient.

\begin{tabular}{|c|c|}
\hline Geometry & Cp [-] \\
\hline GEO $_{01}$ & 0.7151 \\
\hline GEO $_{02}$ & 0.7354 \\
\hline $\mathrm{GEO}_{03}$ & 0.7408 \\
\hline $\mathrm{GEO}_{04}$ & 0.7771 \\
\hline $\mathrm{GEO}_{05}$ & 0.8308 \\
\hline
\end{tabular}

The geometries generated through the interpolation of Bezier curves on the internal diffuser, $\mathrm{GEO}_{04}$ and $\mathrm{GEO}_{05}$, presented the highest $\mathrm{C}_{\mathrm{p}}$ values, with 0.7771 and 0.8308 respectively. In these two cases, the length of the suction tube was purposely reduced to $500 \mathrm{~mm}$. Therefore, it can be concluded that the optimization technique was shown to be adequate in the pursuit of maximizing $C_{p}$ and minimizing the loss coefficient, obeying the lateral restrictions.

Figure 5 presents the contours of pressure local results, in Fig. 6 the streamlines for all analyzed geometries. In Fig. 5, GEO 01 shows that the flat internal diffuser has a high stagnation region, compared to the other geometries, causing greater pressure gradients downstream. $\mathrm{GEO}_{02}, \mathrm{GEO}_{03}$ present larger regions of positive pressure 
downstream, but more uniformly. In $\mathrm{GEO}_{04}$ and $\mathrm{GEO}_{05}$, pressure gradients are more concentrated in the region near the entrance of the draft tube.
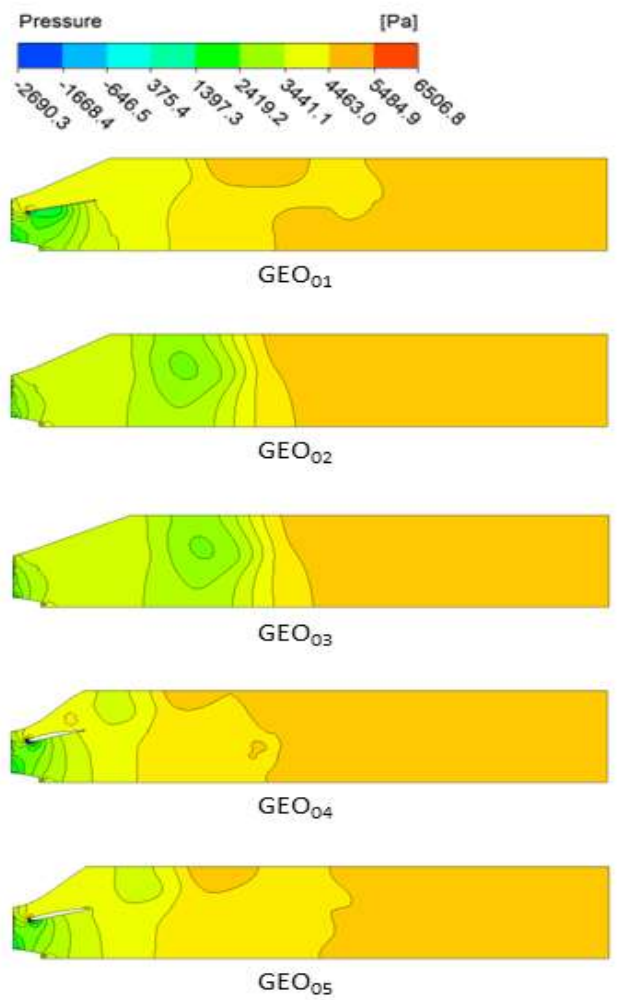

Fig. 5. Contours of pressure.

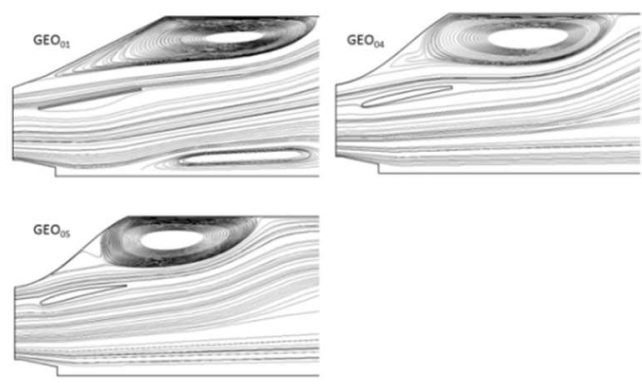

Fig. 6. Streamlines.

Figure 6, shows the streamlines in 2D plane, where the separation regions in all geometries are verified (GEO01, GEO04 and GEO05), however, the $\mathrm{GEO}_{05}$, shows a smaller region of recirculatory flow, result of the optimization process.

The intensity or ratio of turbulence, defined as the relationship between the kinetic energies of the fluctuations and the average field (Eq. (18)); typically, this value can vary around $5 \%$, reaching up to $90 \%$. In hydraulic rotors, turbulence intensity values of up to $20 \%$ have been reported.

In $2 \mathrm{D}$ analysis, turbulence intensity values lesser than $40 \%$ were identified in geometries $\mathrm{GEO}_{04}$ and GEO 05 . At the outlet of the turbine or at the inlet of the draft tube, values of intensity around $3 \%$ were verified, a value that is considered acceptable within the runner channel of hydraulic turbomachines with values of $10 \%$ according to Vivier (1966).

$$
I=\frac{u^{\prime}}{u_{\text {avg }}}
$$

The following geometric values were obtained after the optimization process: diffuser angle $(\theta)=11.2897$ [degrees]; diffuser position $(y$-axis $)=322.7491[\mathrm{~mm}] ; \mathrm{P}_{0}(x)=323.1968$ $[\mathrm{mm}] ; P_{0}(y)=584.3819[\mathrm{~mm}]$. These changes in geometry (added to the hydrodynamic profile of the internal diffuser) yielded the $\mathrm{GEO}_{05}$ with a higher $C_{p}$ (Table 3 ).

\section{THREE-DIMENSIONAL CFD ANALYSIS OF THE DRAFT TUBE}

The three-dimensional analysis of the flow in the draft tube was carried out with the objective of quantifying the $C_{p}$ based on 2D geometries and verifying if the $2 \mathrm{D}$ optimization process can be extended to the three-dimensional field in a qualitative way, so $3 \mathrm{D}$ geometries of $\mathrm{GEO}_{01}, \mathrm{GEO}_{02}$, $\mathrm{GEO}_{03}, \mathrm{GEO}_{04}$ and $\mathrm{GEO}_{05}$ will be presented.

The analyzes were performed only in the draft tube domain for the different geometries. The boundary conditions im-posed were velocity-inlet in the region of inlet and pressure-outlet in the region of outlet. The turbulence model used was the $k-\omega$ SST.

However, in 2D analysis it is not possible to recreate the effects of the structural blades that support the internal diffuser present in the original geometry of the draft tube. For the 3D analysis, the use of the structural blade on $\mathrm{GEO}_{01}$ was considered, to take into account the disturbs that the presence of these blades could cause into the flow, after the runner.

For the 3D approach, periodicity conditions were considered for a lower computational cost.

\subsection{Grid}

As in the 2D plane, structured hexahedral meshes were constructed through the generation of blocks in the 3D domain. To calculate the flow, the $k-\omega$ SST model was also used, which allows the flow behavior to be adequately tracked in the region close to the wall, as well as in the region away from the wall (Menter 1994). Realize that the $k$ - $\omega$ SST turbulence model operates as a switch, activating the $k$ - $\omega$ model for turbulent dissipation and the vorticial region that is found on the mesh element that is closest to the wall, and activating the $k-\varepsilon$ model when the turbulent region is located far away from the wall. In this model, like others, they can integrate wall functions for calculating turbulent viscosity.

The value of $y^{+}$should preferably be within the range of 10 and 200, that is, in the transition region between the region of the viscous sublayer and log-law layer. Therefore, it is possible to pre-dimension the value of the height of the first element on the wall considering the value of $y^{+} \sim 30$, with a growth rate of 1.2. Figure 7 shows the hexahedral mesh for $\mathrm{GEO}_{05}$, 
with emphasis on the growth in the region close to the internal diffuser wall and the internal wall of the draft tube.

To determine the adequate number of elements of the mesh to obtain a reliable result, without having to use the excessive number of elements that would demand a higher computational cost, it is recommended to make an analysis of mesh independence. In this sense, a comparative analysis between two or more grid with different degrees of refinement, must be made (three levels of refinement are recommended) for a more accurate estimate. A methodology applied for this verification is to estimate the discretization error using the GCI - Grid Convergence Index technique (Kwasniewski 2013 and Sakri et al. 2016). The methodology applied to the GCI is based on a mesh refinement error estimator derived from the Richardson extrapolation theory. The result provides a measure of uncertainty of the mesh convergence based on a measure of the percentage by which the calculated value is far or near the asymptotic numerical value. A small GCI value indicates that the calculation is within the asymptotic range of the solution.

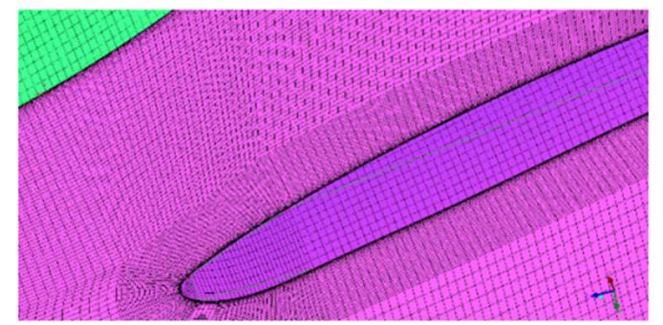

Fig. 7. Hexahedral mesh of the draft tube domain.

The mesh spacing initially had a value of 1 , and then, for each refinement level, it was multiplied by 1.25 . The variable used as an analysis parameter was $C_{p}$. Table 4 presents the analysis performed with three meshes with different degrees of spacing. Grid 2 reached greater convergence proximity to the asymptote curve with grid 3, represented by the GCI value of 0.026 , and the number of elements in the discretization of the computational domain of the draft tube with grid 2 was then determined. This criterion is also applied in unstructured meshes, where the control parameter is the number of elements.

Table 4 GCI results.

\begin{tabular}{|c|c|c|l|}
\hline Grid & $\begin{array}{c}\text { Grid } \\
\text { Spacing }\end{array}$ & $\mathrm{C}_{\mathrm{p}}[-]$ & \\
\hline 1 & 1.000 & 0.56097 & \\
\hline 2 & 1.225 & 0.62355 & $\mathrm{GCI}_{12}=0.168$ \\
\hline 3 & 1.5005 & 0.63428 & $\mathrm{GCI}_{23}=0.026$ \\
\hline
\end{tabular}

\subsection{Numeric solution of three-dimensional analysis}

The analysis for the three-dimensional field was performed in a steady regime with the k- $\omega$ SST turbulence model. The boundary conditions at the inlet were applied using the cartesian velocity components in the $x, y, z$ directions and the static pressure field in the inlet region. As in the 2D approach, these components were obtained after the runner by a previous $3 \mathrm{D}$ simulation of the turbine. At the outlet region, it used the static pressure equal to $0[\mathrm{~Pa}]$ with radial equilibrium pressure distribution as boundary condition.

The SIMPLE method was used for the coupling between pressure and speed. Among the discretization methods, the Green-Gauss Cell-Based method was used for the gradients, the Standard method was used for the pressure discretization, and the First-Order Upwind was used for the convective term. Relaxation factors were adopted for the speed components and for Turbulent Kinetic Energy, in order to control the convergence. Residuals of $10^{-4}$ for the momentum and $10^{-3}$ for $k$ and $\omega$ were monitored.

\subsection{Three-dimensional Analysis Results and Discussion}

Beginning with the analysis of the results obtained for $C_{p}$ and $K$, for the different geometries, as shown in Table 5, it can be seen that there was a gradual increase in $C_{p}$ for each of the geometries, with the lowest value being the original geometry $\mathrm{GEO}_{01}$ with 0.4929 and the highest value for GEO 05 optimized geometry with 0.6830 . This perception reflects directly on the loss coefficient $K$, and on the turbulence in-tensity.

Table 5 3D analysis results.

\begin{tabular}{|c|c|c|c|}
\hline Geometry & $\mathrm{C}_{\mathrm{p}}[-]$ & $\mathrm{K}[-]$ & $\mathrm{I}[-]$ \\
\hline GEO $_{01}$ & 0.4929 & 0.4125 & 0.2704 \\
\hline GEO $_{02}$ & 0.5736 & 0.3318 & 0.1828 \\
\hline GEO $_{03}$ & 0.6018 & 0.3036 & 0.1530 \\
\hline GEO $_{04}$ & 0.6605 & 0.2449 & 0.1860 \\
\hline GEO $_{05}$ & 0.6830 & 0.2224 & 0.1016 \\
\hline
\end{tabular}

At the comparative analysis shown in Fig. 8, between $2 \mathrm{D}$ and $3 \mathrm{D}$ analyses, it is noticed that the $C_{p}$ values obtained in the two-dimensional analysis are higher than the values obtained in the three-dimensional analysis. It is considered that the $3 \mathrm{D}$ simulations represent in a more realistic way the flow field, where all the vorticial structures are quantified in order to increase the energy dissipation mechanisms in the flow, as they can capture the gradients in all directions, including the dissipation of the running machine. On the other hand, it should be noticed that the quality of the mesh was studied in both $2 \mathrm{D}$ and 3D approaches with the objective of reproducing the two-dimensional field in the 3D field.

The following figures show the local results of the flow field. Figures 9 and 10 show the streamlines in the $3 \mathrm{D}$ field. It is verified in the optimized geometry $\mathrm{GEO}_{05}$ (Fig. 9), which has the highest $C_{p}$, that the region of instability or high vorticity is smaller when compared to the other geometries, where the vorticial effects are greater after the exit of the draft tube. 
A. C. Barkett Botan et al. / JAFM, Vol. 14, No. 6, pp. 1617-1633, 2021.

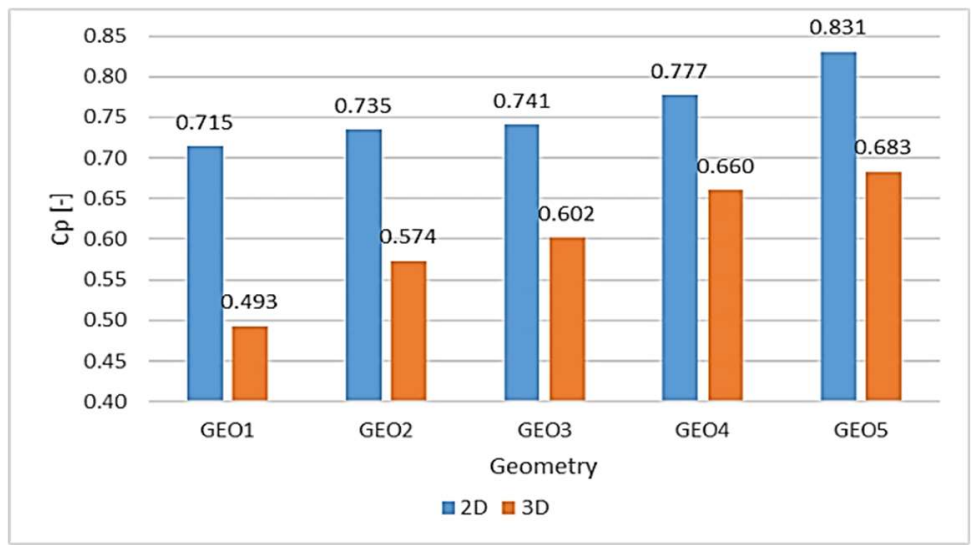

Fig. 8. Comparison of results between 2D and 3D analyses.
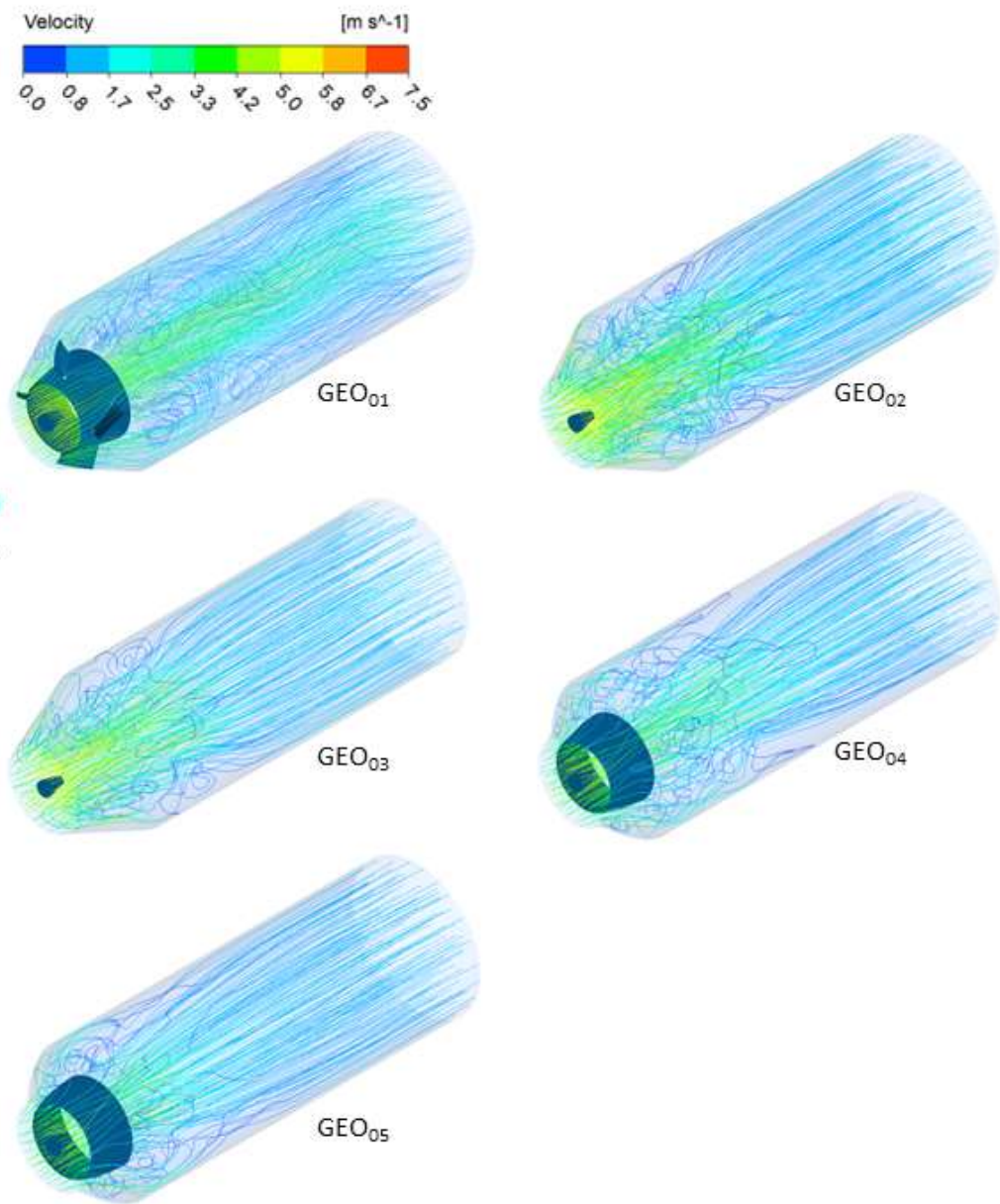

Fig. 9. Velocity streamlines.

In Fig. 10, can be seen a 3D projection of the streamlines for the geometries $\mathrm{GEO}_{01}$ and $\mathrm{GEO}_{05}$ on a longitudinal plane. It can be noticed that in the optimized geometry, there is only the rise of a large vortex between the wall of the tube and the internal diffuser. On the other hand, $\mathrm{GEO}_{01}$ has the formation of more than one structure of vortices that propagates after the outlet of the draft tube, causing the pressure coefficient to be reduced and the loss coefficient to be increased.

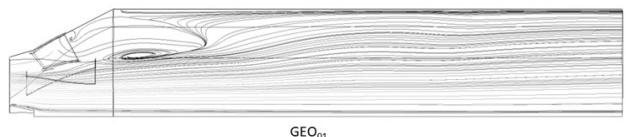

GEO

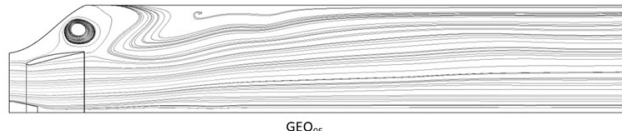

Fig. 10. Streamlines along the 3D draft tube domain $\left(\right.$ GEO $_{01}$ and GEO$\left._{05}\right)$. 


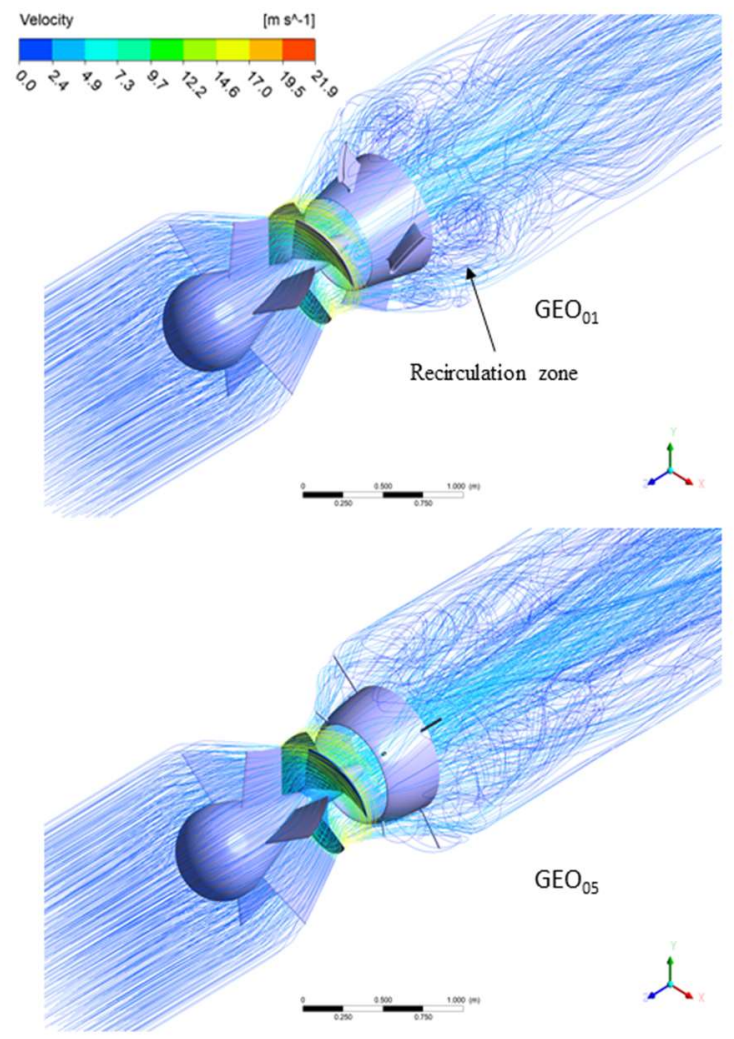

Fig. 11. Streamlines for turbines with draft tube GEO01 (above) and GEO05 (below).

In summary, it can be said that the turbine with the $\mathrm{GEO}_{05}$ geometry draft tube had better performance than the other geometries, with shorter length, ensuring a more compact machine.

\section{SIMULATION OF THE ULH TURBINE WITH THE OPTIMIZED DRAFT TUBE}

In order to consolidate the results of the analysis carried out and described in the previous sections, the flow in the entire turbine was simulated, composed by the three computational domains: inlet domain, composed by the bulb and guide-vanes; the runner domain and the draft tube domain. Thus, two models were analyzed for the purpose of comparing results, considering in the first case the use of the draft tube referring to the geometry $\mathrm{GEO}_{01}$ (original) and the second case using the optimized geometry GEO 05 .

The numerical simulation of the whole turbine was carried out in a steady-state regime, with MRF (Multiple Reference Frame), using stationary periodic domains (inlet domain and draft tube domain) and rotational domain (runner). The connections of the interfaces between the inlet and outlet domains with the runner domain were considered as frozen rotor type. This form of coupling is widely used when the interfaces between the periodic planes are different or even coupling one periodic region to another.

As imposed boundary conditions, it was used for the difference in static pressure related to the net head of 2.5 meters in the inlet and outlet region. To obtain the performance curve, the rotation of the turbine was varied in a range between 200 and $800 \mathrm{rpm}$.

Figure 11 shows the behavior of the streamlines in the turbines composed by $\mathrm{GEO}_{01}$ and $\mathrm{GEO}_{05}$, respectively. On the geometry $\mathrm{GEO}_{05}$, small diameter rods were added to support the internal diffuser on the draft tube wall. These rods were determined by preliminary analysis of internal forces.

The streamlines show larger regions of secondary flows downstream of the internal diffuser in $\mathrm{GEO}_{01}$ compared to $\mathrm{GEO}_{05}$, characterized by low pressure zones, with lots of turbulent dissipations, which contribute to internal losses causing variations on the efficiency of the turbine.

The hydraulic efficiency graphs of the turbines coupled to the $\mathrm{GEO}_{01}$ and $\mathrm{GEO}_{05}$ draft tubes, as a function of rotation $n$ and flow $Q$, are shown in Fig. 12. The turbine assembled with the $\mathrm{GEO}_{05}$ optimized draft tube obtained an increase in hydraulic efficiency of $82 \%$ to $84 \%$, presenting an increase of $2 \%$ over the original geometry $\mathrm{GEO}_{01}$. Despite a relatively low value, this increase represents an improvement in hydraulic efficiency, considering a shorter length draft tube and simpler construction.

In Fig. 12 (a, b) it can be seen that the $\mathrm{GEO}_{05}$ hydraulic efficiency curves present higher values in all flow and rotation ranges and expand the field of operation of the turbine. The hydraulic efficiency curve as a function of the rotation demonstrates that the turbine has characteristics that make it capable of operating in conditions of variable speed, which 


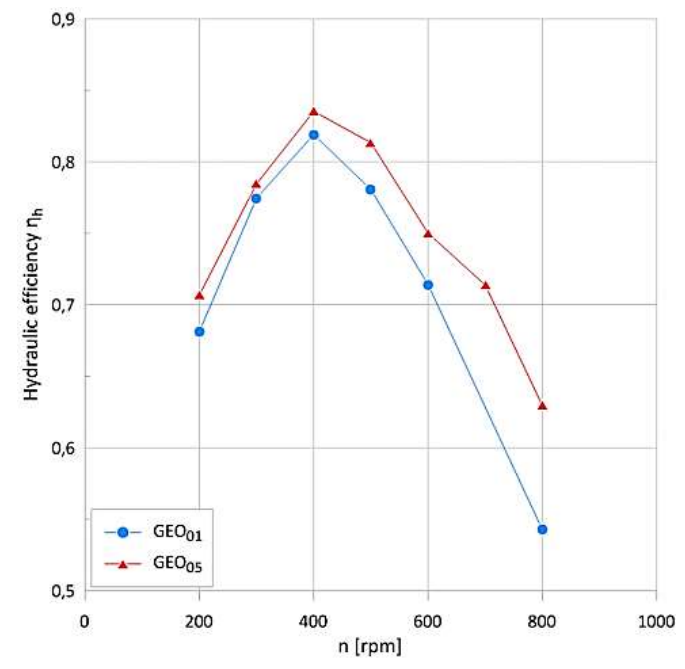

(a)

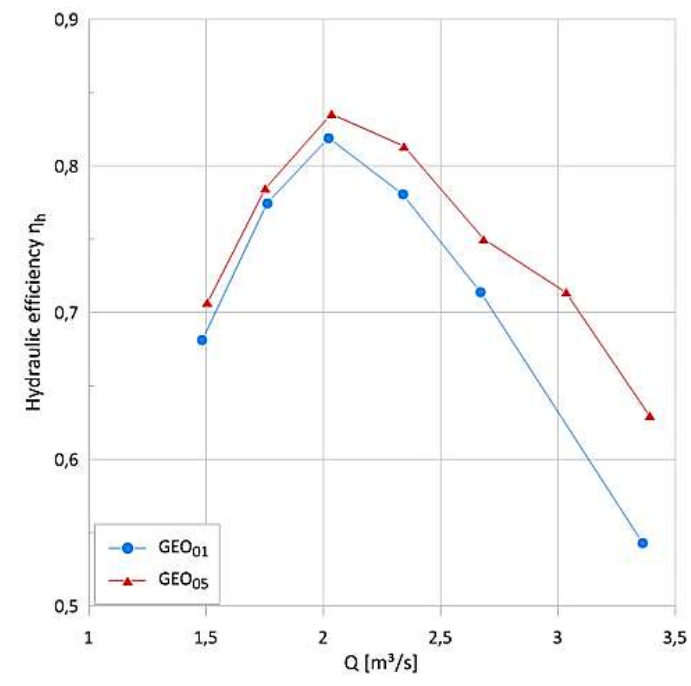

(b)

Fig. 12. Comparative charts of hydraulic efficiency of the ULH turbine built with draft tube geometries (a) GEO $\mathrm{O}_{01}$ and (b) GEO $\mathrm{G}_{05}$.

increases the field of operation of the turbine in ultralow head power plants, where no variable pitch guide-vanes system is used. Variation of head is common in ultra-low head power plants, which implies variable speed. Also, due to the variation in speed, the turbine allows greater variations in the generation load.

\section{CONCLUSIONS}

This work presented a methodology for geometrical optimization of a draft tube from an ultra-low head turbine, aiming to a compact turbine project, where the turbine inlet and outlet flanges can be directly coupled to a low-pressure piping system.

In a first approach in the 2D plane, twelve geometric variables of the draft tube were considered, with restrictions in relation to the length of the tube. The methodology was based on the integration of DOE and the stochastic optimization algorithm, MOSA, automatically through the editing of meshing files in Tlc/Tk language and the numerical solution in Fluent ${ }^{\circledR}$, that allowed the generation of a new draft tube geometry. The objective function of the optimization problem was to maximize the pressure recovery coefficient, $C_{p}$. The optimized geometry obtained showed an increase in the $C_{p}$ value of 0.71516 , from the original geometry, to 0.83080 . This approach proved to be advantageous, since it allows to obtain a qualitative result of the flow behavior and due to its low computational cost, considering the integration with optimization algorithms.

The two-dimensional optimization methodology was extended to a three-dimensional analysis, carried out in two stages: the first stage only on the draft tube, with the pressure and speed of the flow at the runner outlet as inlet boundary conditions, where the $C_{p}$ value was raised for all geometries analyzed in $2 \mathrm{D}$, and a second stage, where the behavior of the complete turbine, composed of the guide vanes and the runner, was evaluated. As result, a more compact turbine was obtained by reducing the length of the draft tube from $671 \mathrm{~mm}$ to $500 \mathrm{~mm}$, with an increase in hydraulic efficiency from $82 \%$ to $84 \%$. There was also an increase in the field of operation of the turbine, within the ranges of variable speed and operational flow. The flow within the optimized geometry draft tube was less disturbed compared to the original geometry draft tube, with less indication of recirculation, which contributes to lower gradients for internal losses. The applied methodology, besides presenting good results, allows to be extended to other similar optimization problems in the design of hydraulic machines.

\section{ACKNOWLEDGEMENTS}

Authors would like to thank Capes (Coordination for the Improvement of Higher Education Personnel), FAPEMIG (Research Support Foundation of the State of Minas Gerais), and CNPq through INCIT INEOF (National Institute of Science and Technology in Ocean and Fluvial Energies).

\section{REFERENCES}

Abbas, A. and A. Kumar, (2017). Development of draft tube in hydro-turbine: a review. International Journal of Ambient Energy 38(3), 323-330.

Adanta, D., Budiarso, Warjito and A. I. Siswantara (2018). Assessment of turbulence modelling for numerical simulations into Pico hydro turbine. Journal of Advanced Research in Fluid Mechanics and Thermal Sciences 46(1), 21-31. ISSN: 2289-7879.

Amani, E, M. R. Akbari and S. Shahpouri (2018). Multi-objective CFD optimizations of water spray injection in gas-turbine combustors. Fuel 227, 267-278. 
Arispe, T. M., W. Oliveira and R. G. Ramirez Camacho (2018). Francis turbine draft tube parametrization and analysis of performance characteristics using CFD techniques. Renewable Energy 127, 114-124, Elsevier.

Bandyopadhyay, S., S. Saha, U. Maulik and K. Deb (2008). A simulated annealing-based multiobjective optimization algorithm: AMOSA. IEEE Transactions on Evolutionay Computation 12(3), 269-283.

Bhattarai, S., K. Dahal, P. Vichare and B. Mishra (2018). CFD based stochastic optimization of Pelton turbine bucket in stationary condition. 9th International Conference on Mechanical and Aerospace Engineering (ICMAE).

Camacho, R. G. R. and J. R. Barbosa, (2005). The boundary element method applied to incompressible viscous fluid flow. Journal of the Brazilian Society of Mechanical Sciences and Engineering, 27(4), 456-462.

Camacho, R. G. R. and J. R. Barbosa, (2008). The boundary element method applied to forced convection heat problems. International Communications in Heat and Mass Transfer, 35(1), 1-11.

Camacho, R. G. R. and N. Manzanares Filho (2005). A source wake model for cascades of axial flow turbomachines. Journal of the Brazilian Society of Mechanical Sciences and Engineering, 27(3), 288-299.

Castilho, L., R. G. R. Camacho and E. R. Silva (2016). Optimized design of linear cascades for turbomachinery applications. Journal of the Brazilian Society of Mechanical Sciences and Engineering, 38(3), 813-825.

Chirkov, D. V., A. S. Ankudinova, A. E. Kryukov, S. G. Cherny and V. A. Skorospelov (2018). Multi-objective shape optimization of a hydraulic turbine runner using efficiency, strength and weight criteria. Structural and Multidisciplinary Optimization 58, 627-640.

Daniels, S. J., A. A. M. Rahat, G. R. Tabor, J. E. Fieldsend and R. M. Everson (2020). Shape optimisation of the sharp-heeled Kaplan draft tube: Performance evaluation using Computational Fluid Dynamics. Renewable Energy 160, 112-126.

Dehghami, M., H. Ajam and S. Farahat (2016). Automated diffuser shape optimization based on CFD simulations and Surrogate modeling. Journal of Applied Fluid Mechanics 9(5), 25272535 .

Galván, S. C. Rubio, J. Pacheco, C. Mendoza and M. Toledo (2013). Optimization methodology assessment for the inlet velocity profile of a hydraulic turbine draft tube: part I - computer optimization techniques. Journal of Global Optimization 55, 53-72.

Gosavi, A. (2003). Simulation-based optimization: parametric optimization techniques and reinforcement learning. Kluwer Academic Publishers.

Herrera, N., S. Galván, J. Camacho, G. Solorio and A. Aguilar (2017). Automatic shape optimization of a conical-duct diffuser using a distributed computing algorithm. Journal of Brazilian Society of Mechanical Sciences and Engineering 39, 4367-4378.

Iovanel, R. G., D. M. Bucur and M. J. Cervantes (2019.a). Study on the accuracy of RANS modeling of the turbulent flow developed in a Kaplan turbine operated at BEP. Part 1 Velocity field. Journal of Applied Fluid Mechanics 12(5), 1449-1461.

Iovanel, R. G., D. M. Bucur and M. J. Cervantes (2019.b). Study on the accuracy of RANS modeling of the turbulent flow developed in a Kaplan turbine operated at BEP. Part 2 Pressure fluctuations. Journal of Applied Fluid Mechanics 12(5), 1463-1473.

Khanjanpour, M. H. and A. A. Javadi (2021). Optimization of a Horizontal Axis Tidal (HAT) turbine for powering a Reverse Osmosis (RO) desalination system using Computational Fluid Dynamics (CFD) and Taguchi method. Energy Conversion and Management 231, 113833.

Kirkpatrick, S., C. D. Gelatt and M. P. Vecchi (1983). Optimization by simulated annealing. Science, 220, 671-680.

Kumar, R., V. S. Kumar, M. M. Butt, N. A. Sheikh, S. A. Khan and A. Afzal (2020). Thermomechanical analysis and estimation of turbine blade tip clearance of a small gas turbine engine under transient operating conditions. Applied Thermal Engineering 179, 115700.

Kwasniewski, L. (2013). Application of grid convergence index in FE computation. Bulletin of the Polish Academy of Sciences, Technical Sciences 61 (1), 123-128.

Launder, B. E. and D.B. Spalding (1974). The Numerical Computation of Turbulent Flows. $J$. High Energy Phys. 10, 269-289.

Martin, J., L. Chang, Swiderski, T. T. Tung, G. L. Tiago Filho, A. J. Rezek, W. Barbosa and A. C. B. Botan (2016). Development of Innovative Ultra Low-head Mini-hydro Turbine-generator System-Laboratory Test Results Report and Field Demonstration Plan. In: Hydrovision International 2016, Minneapolis, USA.

McNabb, J. C. Devals, S. A. Kyriacou, N. Murry, B. F. Mullins (2014). CFD based draft tube hydraulic design optimization. IOP Conf. Series: Earth and Environmental Science 22.

Menter, F. R. (1994). Two-Equation Eddy-Viscosity Turbulence Models for Engineering Applications. AIAA Journal 32 (8), 1598-1605.

Montgomery, D. C. (2005). Design and analysis of experiments. Sixth edition. John Willey \& Sons, New Jersey, USA. ISBN 978-1-118-14692-7. 
Moravec, P. J. Hlinik and P. Rudolf (2016). Optimization of hydraulic turbine diffuser. European Physical Journal Conferences 114, 02079.

Muhirwa, A., W. H. Cai, W. T. Su, Q. Liu, M. Binama, B. Li and J. Wu (2020). A review on remedial attempts to counteract the power generation compromise from draft tubes of hydropower plants. Renewable Energy 150, 743-764.

Muis, A., P. Sutikno, A. Soewono and F. Hartono (2015). Design optimization of axial hydraulic turbine for very low head application. Energy Procedia 68, 263-273.

Mun, C. N., D. C. Ba, X. J. Yue and M. I. Kim (2017). Multi-objective optimization of draft tube in Francis turbine using DOE, RBF and NSGA-II. Preprints.

Nam, D. and C. Hoon Park (2000). Multiobjective simulated Annealing: a comparative study to evolutionary algorithms. International Journal of Fuzzy Systems, 2.

Nam, M. C., B. Dechun, Y. Xiangji and J. Mingri (2018). Design optimization of hydraulic turbine draft tube based on CFD and DOE method. IOP Conf. Series: Earth and Environmental Science, 136.

Nelder, J. A. and R. Mead (1965). A Simplex Method for Function Minimization. The Computer Journal 7 (4), 308-313.

Orso, R., E. Benini, M. Minozzo, R. Bergamin and A. Magrini (2020). Two-objective optimization of a Kaplan turbine draft tube using a Response Surface Methodology. Energies 13, 4899.

Pal, C. (2018). Experimental and CFD analysis of mixed elbow draft tube and comparative analysis with simple elbow draft tube. International Journal for Research in Engineering Application \& Management (IJREAM) 4(3), 15-21.

Pinto, R. N., A. Afzal, L. V. D'Souza, Z. Ansari, A. D. M. Samee (2017). Computational Fluid Dynamics in Turbomachinery: A Review of State of the Art. Arch Computat Methods Eng. 24, 467-479.

Rao, S. S. (2009). Engineering optimization: theory and practice. Fourth edition. John Willey \& Sons, New Jersey, USA.

Rezek, T. J., C R. G. R. amacho, N. M. Filho and E. J. Limacher (2021). Design of a hydrokinetic turbine diffuser based on optimization and computational fluid dynamics. Applied Ocean Research 107, 102484.

Rudolf, P. (2006). Optimization Methods for Hydraulic Machines Design - -Shape Optimization of Swirl Turbine Draft Tube. In Hydroturbo 2006, Slovakia. Conference paper.

Sakri, F. M., M. S. M. Ali and S. A. Z. S. Salim (2016). Computational investigations and grid refinement study of 3D transient flow in a cylindrical tank using OpenFOAM. IOP Materials Science and Engineering, 152(1), 012058.

Santos, I. F. S., R. G. Ramirez Camacho, G. L. Tiago Filho, A. C. B. Botan and B. A. Vinent, (2019). Energy potential and economic analysis of hydrokinetic turbines implementation in rivers: An approach using numerical predictions (CFD) and experimental data. Renewable Energy, 143, 648-662.

Sarmiento, E. A. L., R. G. R. Camacho and W. Oliveira, (2020). Performance analysis of radial-inflow turbine of ORC: new combined approach of preliminary design and 3D CFD study. Journal of Mechanical Science and Technology 34 (6), 2403-2422.

Sarmiento, E. A. L., R. G. R. Camacho, W. de Oliveira, M. Murthi and N.J. Diaz Gautier (2021). Design and off-design performance improvement of a radial-inflow turbine for ORC applications using metamodels and genetic algorithm optimization. Applied Thermal Engineering 183, part 2, 116197.

Silva, E. R., R. G. R. Camacho and N. Manzanares Filho, (2010). Global optimization based on metamodel construction applied to design axial turbomachinery cascades using CFD. In 25th IAHR Symposium on Hydraulic Machinery and Systems, 2010. IOP Conference Series: Earth and Environmental Science 12, 012095.

Silva, E. R., N. Manzanares Filho and R. G. R. Camacho (2012). Metamodelling approach using radial basis functions, stochastic search algorithm and CFD - Application to blade cascade design. International Journal of Mathematical Modelling and Numerical Optimization 3 (1/2), 82-97.

Sritram, P. and R. Suntivarakorn (2017). Comparative study of small hydropower turbine efficiency at low head water. Energy Procedia 138, 646-650.

Straatman, R., A. Eger and C. Morais, (2017). Otimização de turbinas Kaplan "S". $P C H$ Noticias \& SHP News, 78, 23-29, Editora Acta/CERPCH - In Portuguese.

Ulungu, E. L., J. Teghem, P. H. Fortemps and D. Tuyttens (1999). MOSA Method: a tool for solving multiobjective combinatorial optimization problems. Journal of MultiCriteria Decision Analysis 8, 221-236.

Vinagre, M. V. A., C. J. C. Blanco, A. L. A. Mesquita, A. C. Melo Lima and L. A. L. Bello (2016). Otimização do Uso de Turbinas Axiais em Pequenas Centrais Hidrelétricas da Amazônia. Revista Brasileira de Recursos Hidricos, 21, 88-98. (In Portuguese).

Vivier, L. (1966). Turbines Hydrauliques et Leur Regulation. Éditions Albin Michel, Paris, France. EAN13 : 9782226161802. 
A. C. Barkett Botan et al. / JAFM, Vol. 14, No. 6, pp. 1617-1633, 2021.

Wilhelm, S., G. Balarac, O. Métais and C. Ségoufin (2016). Head losses prediction and analysis in a bulb turbine draft tube under different operating conditions using unsteady simulations. In 28th IAHR Symposium on Hydraulic Machinery and Systems, 2016. IOP Conference Series: Earth and Environmental Science, 49:022010.

Yakhot V., S. A. S. Orszag, T. B. Thangam, Gatski and C. G. Speziale (1992). Development of turbulence models for shear flows by a double expansion technique. Physics of Fluids A, 4(7), $1510-1520$.

Yang, W., Y. Wu and S. Liu (2010). A modification method on runner blades in a Bulb turbine. In 25th IAHR Symposium on Hydraulic Machinery and Systems, 2016. IOP Conference Series: Earth and Environmental Science 12, 012003.

Zhou, D. and Z. Deng (2017). Ultra-low-head hydroelectric technology: A review. Renewable and Sustainable Energy Reviews 78, 23-30.

Zhou, D., J. Gui, Z. D. Deng, C. Huixiang, Y. You, A. Yu and C.Yang, (2019). Development of an ultra-low head siphon hydro turbine using computational fluid dynamics. Energy 181, 4350 